\title{
Effects of Teachers' Utilisation of Tiered Home Assignment on Students' Achievements in Mathematics
}

\author{
Victoria Olusola Olisama and Olukemi Mary Odumosu \\ Adeniran Ogunsanya College of Education, \\ Otto-Ijanikin, Lagos Nigeria \\ Fisayo Areelu \\ Micheal Otedola College of Primary Education, \\ Epe, Lagos, Nigeria
}

\begin{abstract}
This research discusses the effect of Tiered Mathematics Home Assignments (T.M.H.A.) on the academic achievements of junior secondary school students. Gone are the days when only the students who could not answer mathematics questions correctly in the classroom were given assignments to improve their competence in the subject. Mathematics assignments are now given to every student in order to minimize the rate of failure. However, not all mathematics teachers can effectively construct appropriate assignments which can improve the students' understanding of the subject. 631 students from 9 junior secondary schools (JSS) in Lagos took part in this study. The results revealed significant interaction effects of T.M.H.A. on students' ability levels and achievement in mathematics. During this study, we observed that students who were given relevant home assignments (as per T.M.H.A.) had improve their competence in the subject by a higher amount than those who were exposed only to regular assignments. The results also show that there is a significant effect of gender on students' mathematics achievement and ability levels. Similarly, the findings show that there is a significant effect of school type on students' mathematics achievement and ability levels. In general, male students tend to perform better than female students and students from private schools performed slightly better. It was also observed that some mathematics teachers paid little attention to the purpose, design and standard of the mathematics homework assigned to the students. Thus, we recommended that a course on differentiated M.H.A. (Mathematics Home Assignment) should be included in the teachers' training mathematics curriculum and frequent seminars should be organized for teachers by the school administrators on the effective use of T.M.H.A.
\end{abstract}

Keywords: tiered mathematics home assignment; teachers' training; mathematics curriculum; gender; school type. 


\section{Introduction}

A main challenge for education stakeholders (teachers, curriculum planners, commissioners and the Minister of Education) is the quality of teaching and learning in mathematics. Over the years, many educators have shown concern over improving students' achievement in mathematics (Cooper et al., 1998). Currently, researchers are interested on how students should learn better for an improved performance in mathematics (Areelu \& Dawodu, 2015; FernandezAlonso et al., 2017). The researchers emphasize on new instructional design techniques to develop individuals who can understand and apply fundamental mathematics concepts. They are also working on methodologies on how to provide instructional environments, conditions, methods, and solutions that can achieve learning goals for students with different skills and ability levels. Attempts were also made to create innovative instructional approaches and techniques for students to become successful learners.

The teaching of mathematics is indeed a challenging and exciting adventure which deserves special skills on the part of the teacher and positive attitude towards learning on the part of the students. One of these special skills is the effective utilization of home assignments (H.A.) (Cheema, 2011). Homework refers to the task given by the teachers to the students to do at home. It is an intersection between home and school. An assignment, on the other hand, is a set of tasks or piece of work assigned to someone in a course of study. Mathematics Home Assignment (M.H.A.) deals only with the mathematics course content. M.H.A. may be designed to improve what student have learned in the mathematics course, prepare them for the next lessons, improve what they know by applying it to new situations, or to integrate their abilities by the application of different skills to one larger or more complex task. Home assignments allow parents to participate in their children's education. Home assignments may involve a quantity of reading to be performed, some writing to be done and solve some logical or mathematical problems (Kohn, 2007).

Tiered assignment is a meaningful strategy to differentiate learning through homework. It helps teachers to satisfy the needs of the students using different instructional levels. The main idea is that assignment questions are arranged in a hierarchy from less to more complex. Students obtain better scores when assessments are arranged from simple ones to more complex ones. This is in line with the Bloom's taxonomy (Bloom, 1969) which contains the three overlapping domains: cognitive, psychomotor and affective. Assessment-based tiering allows students to work in a convenient environment and in a state of little challenge (Anderson et al., 2000; Pablico, Diack \& Lawson, 2017).

The poor academic achievement of students, particularly in mathematics has been a great concern to all stakeholders, (Adebule, 2014; Roschelle, 2016). This is because mathematics is among the basic requirements for entrance into the different stages of higher education. It is also the bedrock of all science and technologically based subjects. This consistent poor performance of students in mathematics calls for serious rational action to improve the situation. 
Due to the fact that mathematics is a discipline that encourages problem solving, great achievement can emerge if students participate in regular M.H.A. given by the teachers. For many reasons, a great number of secondary school teachers have traditionally given assignment to their students, using no particular format, (Cooper et al., 1998; Doorn, Janssen \& O'Brien, 2010). It is generally opined that regular H.A. presents students with the opportunity to focus on the concepts, and improve specific skills introduced and discussed in the classroom. On the other hand, a teaching strategy that incorporates differentiated assignment, welldesigned lessons and formative activities would equip students with a deeper understanding of the concepts, principles or topics dealt with in the class. Also, tiered assignments can instil within students a strong work ethic, the ability to work and think independently and can also enhance their sense of accomplishment and confidence. Furthermore, group assignments enable students to work collaboratively outside the classroom and without teachers' supervision (Howie, 2012; Fernandez-Alonso et al., 2016).

\section{Statement of Problem}

Despite the fact that regular assignments are believed to be a positive factor in students' understanding of a subject (Cheema, 2011), many teachers and parents or guardians complain that many of their students or wards do not always complete their assignments to reap the benefits.

Also, many students see regular M.H.A. as an unfinished task of the teacher drawn from lack of knowledge about the topic. And such M.H.A. has become a daily food for many students in several schools. Teachers give M.H.A. to students almost every day using no particular format. But only a few of the students finish their assignments and submit them to the teacher on time. Most students think that M.H.A. are not necessary for them. Some of the students skip classes simply because they have not finished the M.H.A. and some students choose to come to school very early in the morning to copy answers from their friends' assignments. Some students even give their M.H.A. to somebody at home to solve (Doorn et al., 2010; Landers \& Reinholz, 2015).

Furthermore, researchers such as Kohn (2007), Bennett \& Kalish (2007) have negative opinions about assignments, arguing that students who find it difficult to complete assignments because of their under-privileged family backgrounds are marginalized. They are of the opinion that teachers, in general, are not well trained on how to construct effective assignments. Often teachers give assignments on topics that have not been taught, which should not be the case. Furthermore, some authors have called for the abolition of H.A. stating that it wastes students' time and brings no visible advantage and that it is of meagre educational value for students younger than 15 years and may not even have any positive effects on their learning or understanding of the subject Haddock, 2006; Kohn, 2007). In this study, we introduce the Tiered Mathematics Home Assignment (T.M.H.A.) which differentiates assignment in a unique format, from simple to complex ones based on topics already taught and investigate how T.M.H.A. affects mathematics achievement and ability levels of students below 15 years from junior secondary schools (JSS) in the Lagos State, Nigeria. 


\section{Research Problems}

Based on the problems mentioned above, the following questions were raised:

i. What effect can teachers' utilization of T.M.H.A. have on JSS students' ability levels in mathematics?

ii. What effect can Teachers' utilization of T.M.H.A. have on JSS students' achievement in mathematics?

iii. Does teachers' utilization of T.M.H.A. have any effect on the ability levels of JSS students in mathematics based on gender?

iv. Does teachers' utilization of T.M.H.A. have any effect on the achievement of JSS students in mathematics based on gender?

v. Is there any effect of teachers' utilization of T.M.H.A. on ability levels of JSS students in mathematics based on school type?

vi. Is there any effect of teachers' utilization of T.M.H.A. on achievement of JSS students in mathematics based on school type?

\section{Research Hypotheses}

The following hypotheses were raised:

H01. There are no significant effects of: (a) tiered home assignment, (b) gender and (c) school type, on students' (i) achievement and ii) ability levels in mathematics.

H02. There is no significant interaction effects of gender and school type on students' (i) achievement and (ii) ability levels in mathematics.

\section{Research Methodology}

In this section, we discuss the design, subjects, instruments, data collection and data analysis procedures of the study.

Students' achievement levels were determined by cross-tabulating ability levels (low, average, high) with gender (male or female) and school type (public or private) along with the group of students who were given the tiered assignment adopted by the researchers from five recently completed topics and the group of students who were given regular assignments prepared by the teachers on the same topics. Achievement in this study is the mean scores of students from the pre- and post-tests. The scores were further classified into low, average and high ability levels. Those with scores between 0-49 were grouped as low ability, 50-69 as average ability and 70-100 as high.

Table 1. Participants in the study

\begin{tabular}{|l|l|c|}
\hline \multirow{3}{*}{ Gender } & Type of Participants & Number of Participants \\
\hline \multirow{3}{*}{ School Type } & Male students & 267 \\
\cline { 2 - 3 } & Female students & 364 \\
\hline \multirow{4}{*}{ Treatment Group } & Government- owned & 353 \\
\cline { 2 - 3 } & Privatively-owned & 278 \\
\cline { 2 - 3 } & Without Home Assignments & 228 \\
\cline { 2 - 3 } & Regular Home Assignments & 220 \\
\cline { 2 - 3 } & Tiered Home Assignments & 183 \\
\hline
\end{tabular}


The participants of this study were 631 Junior Secondary School 2 students drawn using stratified random sampling technique from all Junior Secondary Schools Students in Badagry, Alimosho, Eti-Osa Local Government Areas in Lagos State. From Badagry and Eti Osa, 214 (120 public and 94 private) students were selected, while 203 (113 public and 90 private) students were selected from Alimosho. Two public schools and one private school were randomly selected from each of the schools in the three Local Government Areas. A total of nine schools were used namely: (1) Badagry: Araromi Ilogbo JSS, Badagry Junior Grammar School (public) and Javy College (private), (2) Alimisho: Abesan High School, Command Secondary School (Public) and Alpha Comprehensive College (private), (3) Eti Osa: Ilasan JSS, Eti Osa Community Junior High School (public) and Adrao International School (private).

\section{Research Instruments}

The instruments used in this study are:

- Student' Diagnostic Test (SDT)

- Students' Mathematics Achievement Tiered Home Assignment (SMATHA)

- Students' Continuous Assessment in Mathematics (SCAM)

- Teachers' Mathematics Assignment Rating Scale (TMARS)

The SDT consists of 9 questions from 3 topics which were recently completed in the classroom. These 3 topics were chosen by allowing the students to choose from the entire set of completed topics so that they may avoid the difficult ones which they would not be able to solve independently.

The SMATHA or T.M.H.A. is a 15-item mathematics achievement tiered home assignment which is used to find out the effect on students' achievement and ability levels in mathematics. It consists of 3-tiered mathematics home assignment in the order of remembering, understanding and applications, arranged from simple to complex based on the topics already taught by the teachers.

The SCAM was the assessment obtained from each school and analyzed using $25^{\text {th }}$ percentile, 50th percentile and 75th percentile for low, average and high ability levels respectively.

The SMATHA yielded a Spearman' rho reliability coefficient of 0.71 while SDT and SCAM produced a reliability of 0.75 and 0.84 , respectively when using the Gutman's split-half reliability method.

The TMARS was used to obtain the reliability and validity of the mathematics assignment prepared by the teachers.

The topics selected were fractions, word problems leading to linear equations and angle of elevation and depression. The teachers taught the entire 631 students for three weeks taking the topics one after the other and gave regular assignments to the control group of 220 students. The researchers also gave SMATHA to the experimental group of 183 on the same topics while the 
remaining 228 students were not given any assignments. Finally, the SDT was administered to all the students.

\section{Data Collection Procedure}

The students were divided into three groups, normal, control and experimental after the normal teaching by their mathematics teachers using SCAM. The teachers gave regular assignment to the control group and the researchers gave SMATHA to the experimental group. The completed assignments were collected and marked by the research assistants. The results were ranked into the three categories: 1-low, 2-average and 3-high. SDT was later administered and ranked to test the students' ability levels and achievement. The students were allowed to collaborate because they were not preparing for any internal or external examination and the researchers were also able to rely on the helpful assistance of the research assistants. Each researcher was assisted by one research assistant for each local government area and the study was done without disrupting the regular programme of the schools.

\section{Data Analysis Procedure}

The hypotheses were tested using the Multivariate Analysis of Covariance (MANCOVA). It was used to discuss the direction of possible significant effects. Bar chart was used to represent the data.

\section{Results and Discussion of Findings}

In this section, we state and discuss the findings.

\section{Research Question 1:}

What effect can teachers' utilization of T.M.H.A. have on JSS students' ability levels in mathematics?

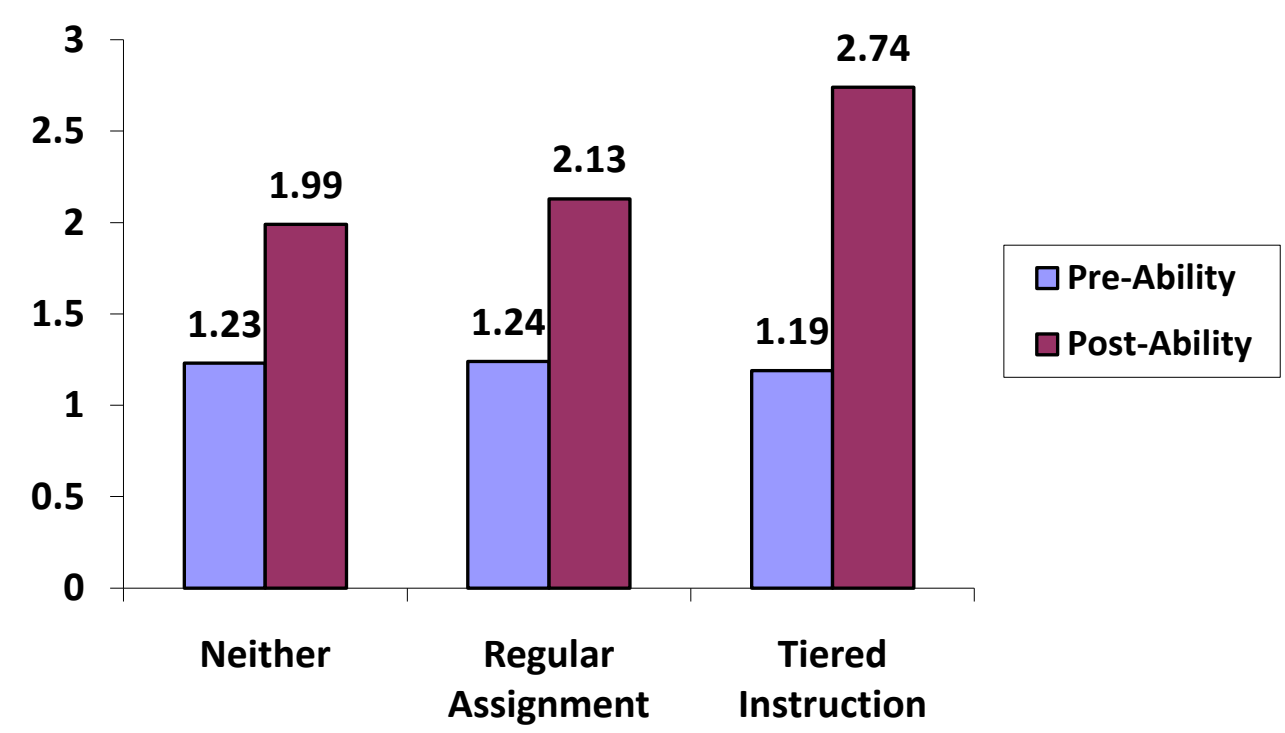

Figure 1: Effect of teachers' utilization of T.M.H.A. on students' ability levels in mathematics 
Figure 1 shows the pre- and post- ability of the three groups of participants. Students who were given no assignments progressed the least by a score of 0.76 , while students who were given the tiered assignments progressed the most by a margin of 1.55 . Those with regular assignments progressed by 0.89 . The average ability of the participants was comparable at the start. This finding indicates that teachers' utilization of T.M.H.A has a higher positive effect on students' ability level in mathematics.

\section{Research Question 2:}

What effect can teachers' utilization of T.M.H.A. have on JSS students' achievement in mathematics?

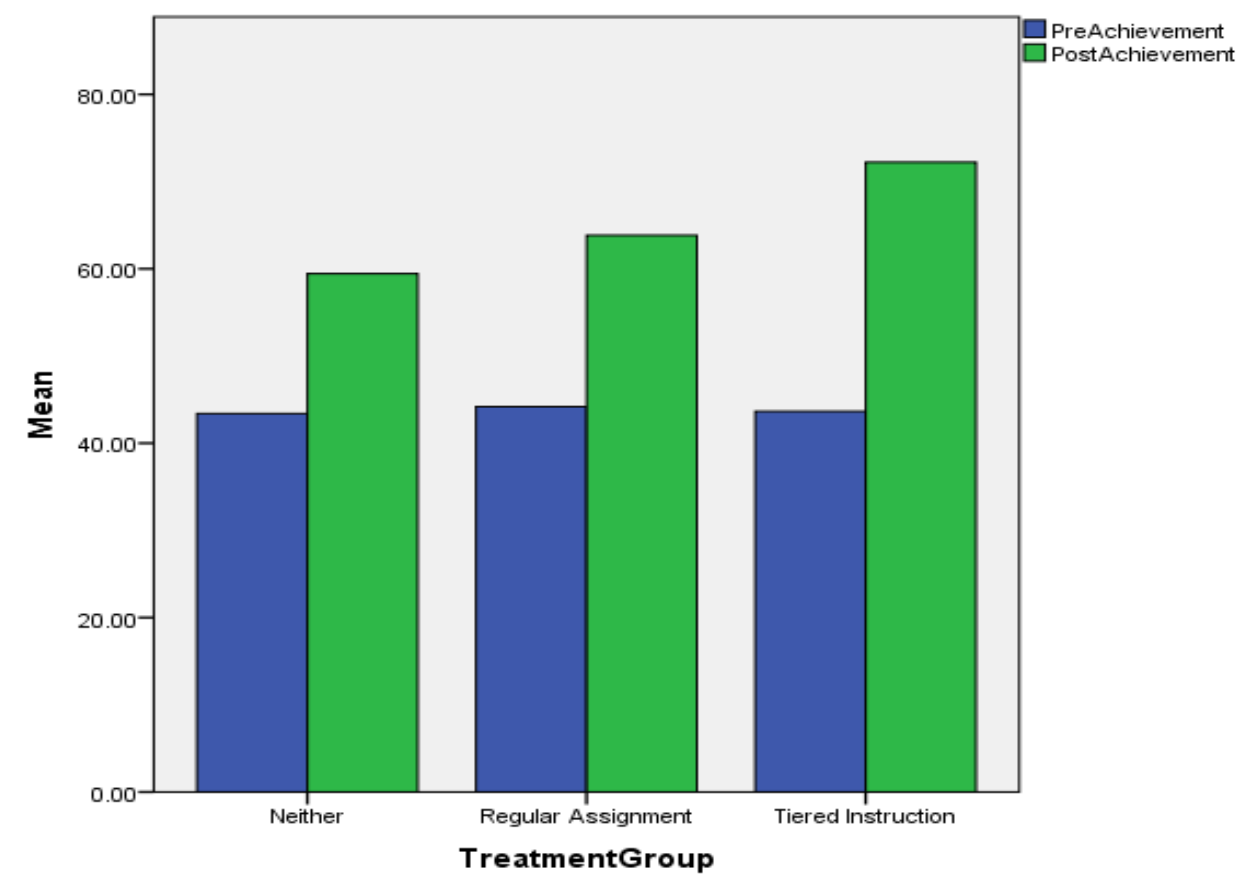

Figure 2: Effect of teachers' utilization of T.M.H.A. on students' achievement in mathematics

Figure 2 shows the pre- and post- achievements of the three groups of participants. Students who were given no assignments progressed the least by $15 \%$ only from $43 \%$ to $58 \%$, while students who were given the tiered assignments progressed the most by $27 \%$. Those with regular assignments progressed by $19 \%$. The average achievement of the participants was similar at the start. This finding indicates that teachers' utilization of T.M.H.A has a higher positive effect on students' achievement in mathematics.

\section{Research Question 3:}

What effect can teachers' utilization of T.M.H.A. have on JSS students' ability levels in mathematics based on gender? 


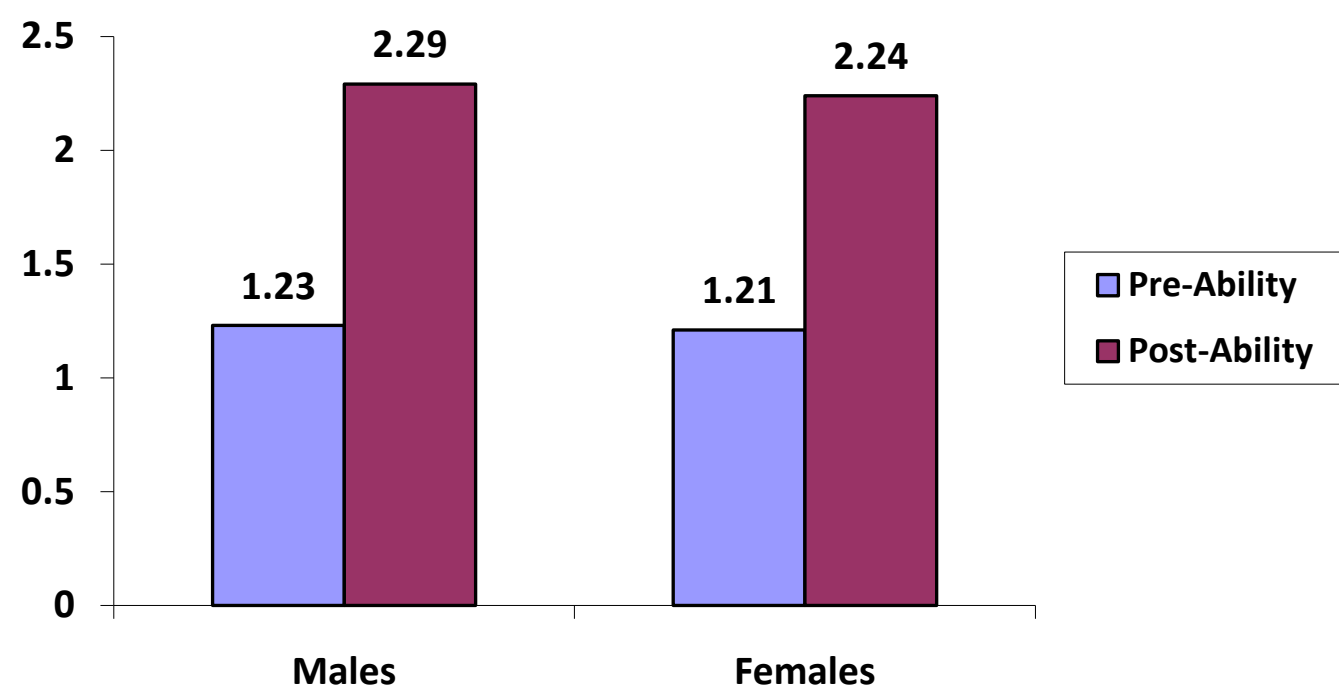

Figure 3: Gender effects of teachers' utilization of T.M.H.A. on students' ability levels in mathematics

Figure 3 shows that at the start both the male and female students had similar ability levels in mathematics. However, at the end of the study, we saw that the ability of both groups has increased by a score of more than 1 . The increase is slightly higher in male students, but it is not significantly different from the score achieved by female students. Thus, our findings indicate that teachers' utilization of T.M.H.A. have had a positive effect on students' ability levels in mathematics on both genders.

\section{Research Question 4.}

What effect can teachers' utilization of T.M.H.A. have on JSS students' achievement in mathematics based on gender?

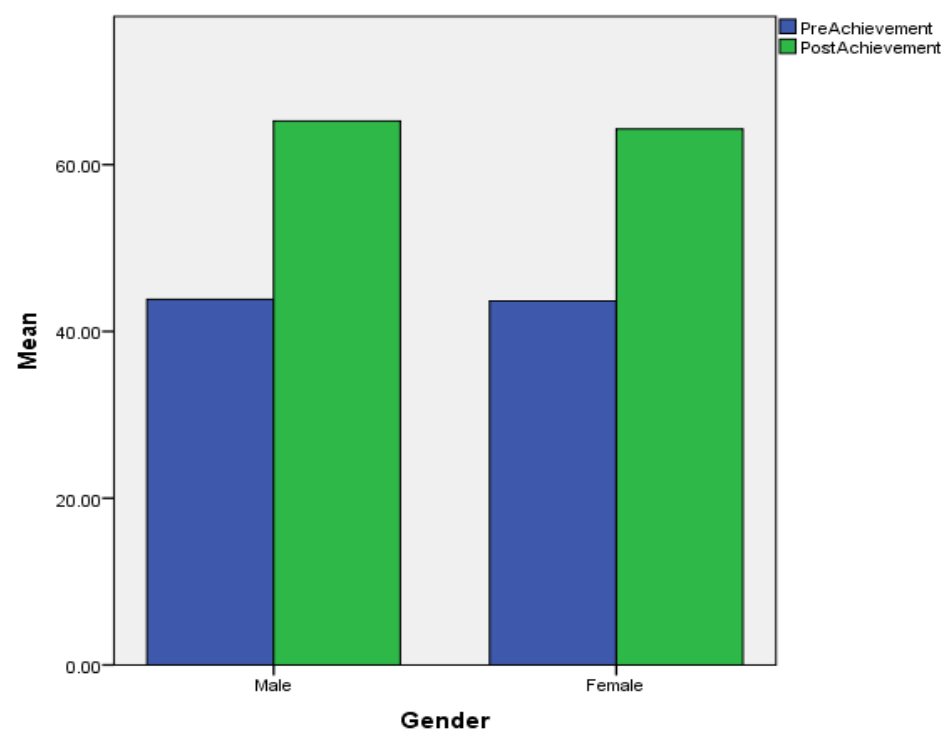

Figure 4: Effect of teachers' utilization of T.M.H.A. on students' achievement in mathematics based on gender 
Figure 4 shows that at the start both the male and female students had similar achievement $(43 \%)$ in mathematics. However, at the end of the study, we saw that the mean achievement of both groups has increased to $66 \%$ and $65 \%$ respectively. The increase is slightly higher in male students, but the difference is not significant. Thus, our findings indicate that teachers' utilization of T.M.H.A. have had a positive effect on students' achievement in mathematics on both genders.

\section{Research Question 5:}

What effect can teachers' utilization of T.M.H.A. have on JSS students' ability levels in mathematics based on school type?

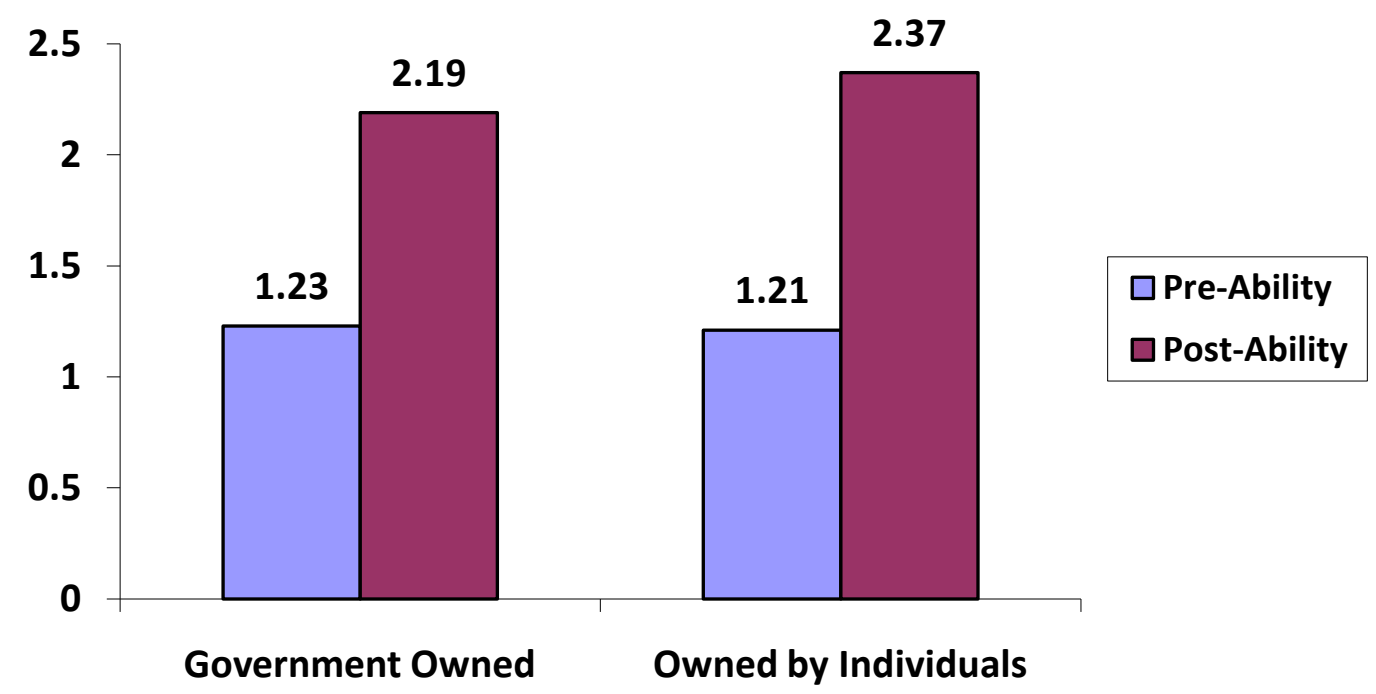

Figure 5: Effect of teachers' utilization of T.M.H.A. on students' ability levels in mathematics based on school type

Figure 5 shows that at the start both students from public and private institutions had similar ability levels in mathematics. However, at the end of the study, we saw that the ability of both groups has increased by significant amounts. The increase is higher in students from private institutions. Thus, our findings indicate that teachers' utilization of T.M.H.A. have had a positive effect on students' ability levels in mathematics on students from both types of institutions.

\section{Research Question 6:}

What effect can teachers' utilization of T.M.H.A. have on JSS students' achievement in mathematics based on school type? 


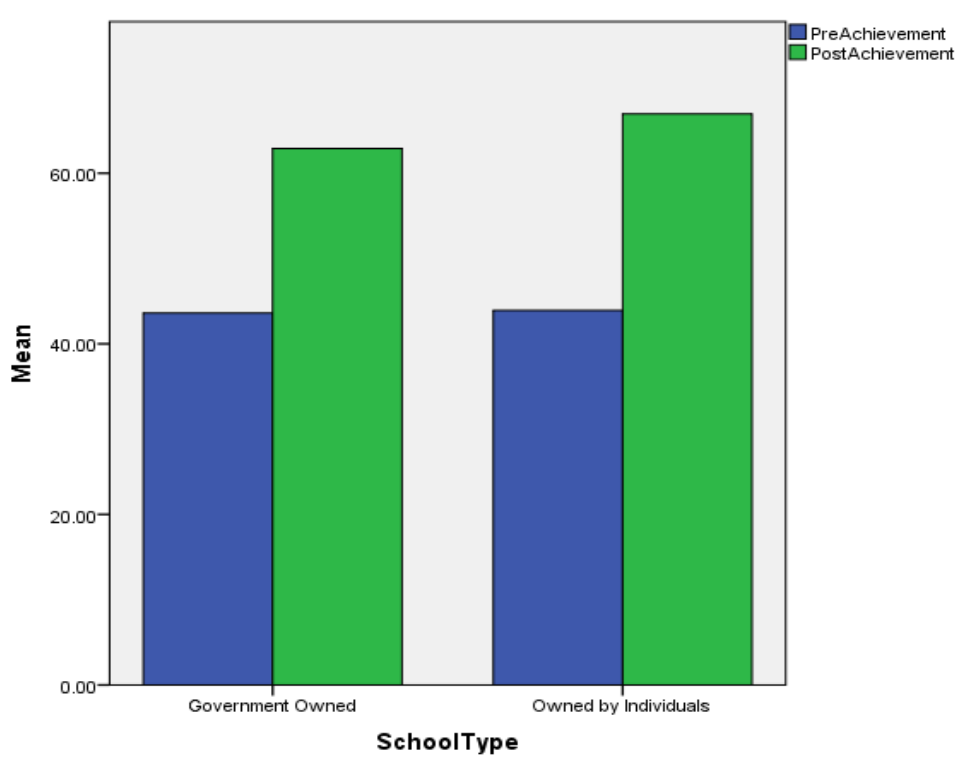

Figure 6: Effect of teachers' utilization of T.M.H.A. on students' achievement in mathematics based on school type

The results in Figure 6 show that both government-owned and privately-owned school students improved their low achievement score of $44 \%$ to average achievement scores of $62 \%$ and $68 \%$, respectively, after the study. The increase as slightly higher for students form private institutions. This implies that teachers' utilization of T.M.H.A. has had a positive effect on their achievement levels in mathematics based on both types of school.

Table 2. Effects of T.M.H.A. on students' mathematics assignment

\begin{tabular}{|l|l|r|c|r|c|}
\hline Source & $\begin{array}{l}\text { Dependent } \\
\text { Variable }\end{array}$ & $\begin{array}{c}\text { Type III } \\
\text { Sum of Squares }\end{array}$ & df & F & Sig. \\
\hline \multirow{3}{*}{ Corrected Model } & Post-Achievement & $20746.068 \mathrm{a}$ & 9 & 48.382 & .000 \\
\cline { 2 - 6 } Intercept & Post-Ability Levels & $54.959 \mathrm{~b}$ & 9 & 38.109 & .000 \\
\hline \multirow{3}{*}{ Pre-Ability Levels } & Post-Achievement & 6633.259 & 1 & 139.224 & .000 \\
\cline { 2 - 6 } & Post-Ability Levels & 7.454 & 1 & 46.518 & .000 \\
\hline \multirow{3}{*}{ Pre-Achievement } & Post-Achievement & 15.577 & 1 & .327 & .568 \\
\cline { 2 - 6 } & Post-Ability Levels & .046 & 1 & .290 & .591 \\
\hline \multirow{3}{*}{ Gender } & Post-Achievement & 13.943 & 1 & .293 & .589 \\
\cline { 2 - 6 } & Post-Ability Levels & .007 & 1 & .042 & .837 \\
\hline \multirow{2}{*}{ School Type } & Post-Achievement & 1827.919 & 1 & 38.366 & .000 \\
\cline { 2 - 6 } & Post-Ability Levels & 1.446 & 1 & 9.023 & .003 \\
\hline \multirow{2}{*}{ Treatment Group } & Post-Achievement & 1075.137 & 1 & 22.566 & .000 \\
\cline { 2 - 6 } & Post-Ability Levels & 1.455 & 1 & 9.081 & .003 \\
\hline \multirow{2}{*}{ Gender * School Type } & Post-Achievement & 6606.516 & 2 & 69.331 & .000 \\
\cline { 2 - 6 } & Post-Ability Levels & 22.620 & 2 & 70.584 & .000 \\
\cline { 2 - 6 } & Post-Achievement & .000 & 0 &. &. \\
\hline
\end{tabular}




\begin{tabular}{|l|l|r|c|r|c|}
\hline \multirow{2}{*}{$\begin{array}{l}\text { Gender * Treatment } \\
\text { Group }\end{array}$} & Post-Achievement & 10.392 & 2 & .109 & .897 \\
\cline { 2 - 6 } $\begin{array}{l}\text { School Type * } \\
\text { Treatment Group }\end{array}$ & Post-Ability Levels & .156 & 2 & .488 & .614 \\
\hline \multirow{2}{*}{$\begin{array}{l}\text { Gender * School Type } \\
\text { * Treatment Group }\end{array}$} & Post-Achievement & 1.397 & 1 & .029 & .864 \\
\cline { 2 - 6 } & Post-Ability Levels & .150 & 1 & .938 & .333 \\
\hline \multirow{3}{*}{ Error } & Post-Achievement & .000 & 0 &. &. \\
\hline \multirow{2}{*}{ Total } & Post-Ability Levels & .000 & 0 &. &. \\
\hline & Post-Achievement & 29587.267 & 621 & & \\
\hline \multirow{2}{*}{ Corrected Total } & Post-Ability Levels & 99.507 & 621 & & \\
\cline { 2 - 6 } & Post-Ability Levels & 3427.000 & 631 & & \\
\cline { 2 - 6 } & Post-Achievement & 50333.334 & 630 & & \\
\cline { 2 - 6 } & Post-Ability Levels & 154.466 & 630 & & \\
\hline
\end{tabular}

Note: df stands for degree of freedom, F stands for Multivariate Analysis of Covariance (MANCOVA) while sig or $\mathrm{p}$ stands for the significant level. Sig is the cliterion which is used to make the decision, i.e., either to reject the null hypothesis or not. If $\mathrm{p}<0.05$, the null hypothesis is rejected, but if $\mathrm{p}>0.05$, the null hypothesis is not rejected.

\section{Testing of the Hypotheses:}

H01. The results, F $(2 ; 621)=69.33 ; p<0.05$ and $F(2 ; 621)=70.58 ; p<0.05$ show that there is a significant effect of treatment on students' mathematics achievement and ability levels respectively.

Similarly, the results, $\mathrm{F}(1 ; 621)=38.37 ; \mathrm{p}=0.00$ and $\mathrm{F}(1 ; 621)=9.02 ; \mathrm{p}=0.003$ show that there is a significant effect of gender on students' mathematics achievement and ability levels respectively.

In the same vein, the results, $\mathrm{F}(1 ; 621)=22.57 ; \mathrm{p}=0.00$ and $\mathrm{F}(1 ; 621)=9.08 ; \mathrm{p}=$ 0.003 show that there is a significant effect of school type on students' mathematics achievement and ability levels respectively.

H02. The result does not reject H02. It shows that there is no interaction effects of treatments, gender and school type on students' achievement and ability levels in mathematics.

The implication of the study is that T.M.H.A. is of great importance in improving JSS students' achievement and ability levels in Mathematics, irrespective of their gender or school type. The results show that SMATHA was most effective at improving students' ability levels and achievement scores in mathematics than regular assignments. These findings are in contradiction to the views asserted by Haddock (2006) and Kohn (2007), who consider assignments as a waste of precious time as they have a meagre education value for young children below 15 years old. 
This study further showed that JSS students were encouraged to complete their T.M.H.A. because the questions were interesting, and they were aware that feedback would not be delayed. A motivation to complete M.H.A. faithfully was built. This is in line with the findings of Fernandez-Alonso et al. (2016) who stated that students who receive prompt feedback on their homework are more motivated to perform better.

Finally, the study reveals that teachers' utilization of T.M.H.A. yields an improved students' achievement and ability levels in Mathematics, which is in line with the result of Roschelle (2016) and Fan et al. (2017) who view homework as a vehicle for students' improvement in mathematics. Moreover, Olisama and Appah (2010) also stated that the positive use of instructional materials improves learners' knowledge and can contribute to the development of a nation.

\section{Recommendations}

To increase teacher's utilization of T.M.H.A. for JSS students' academic performance, the following recommendations are made:

- The study recommends the use of T.M.H.A. to mathematics teachers so that students can complete their assignments within a time frame to reap the benefits.

- Mathematics teachers should be thought how to prepare and use T.M.H.A. so that students can easily solve and improve their understanding of the concept and develop positive interest in the subject.

- Regular seminars and symposium on effective utilization of T.M.H.A. should be organized by the school for mathematics teachers.

- JSS teachers should give T.M.H.A. only on topics that have been taught.

- Curriculum planners should include the application of T.M.H.A. in the curriculum.

- JSS students should be advised on the importance of personally completing their T.M.H.A. for an improved achievement in mathematics.

- The Ministry of Education and school managers should work together to sensitize parents on the importance of T.M.H.A.

\section{Conclusion}

T.M.H.A. is an important strand of the JSS school mathematics education. Through T.M.H.A., students willingly make research and give relevant answers to mathematical questions studied at school which improve their assimilation of the concepts. Students are taught new content at school and later in the day through T.M.H.A., they focus on conceptual understanding, of what was taught earlier. Constant modification of T.M.H.A. is one of the very important features of mathematics teaching in secondary schools. This study has shown that an effective utilization of T.M.H.A. can improve students' achievement and ability levels in mathematics significantly and better than regular assignments. Thus, from all perspectives, homework for mathematics cannot be abolished as it has the capacity to improve students' achievement if the exercises are well-tiered. 


\section{References}

Adebule, S. O. (2014). The effect of homework assignment on Mathematics achievement of Secondary School Students in South West Nigeria. Journal of Education Practice, 5(28).

Anderson, L. W., Krathwohl, D. R., Airasian, P. W., Cruikshank, K. A., Mayer, R. E., Pintrinch, P. R., Raths, J., \& Wittrock, M. C., (2000). A taxonomy for learning and assessing: A revision of Bloom's taxonomy of education objectives. New York: Pearson.

Areelu, F., \& Dawodu, O. A. (2015). Effects of Jigsaw and Individual Personalization Instructional Strategies on Senior Secondary School Students' Achievement in Mathematics. Academic Journal of Science, 4(3), 265-282.

Bennett, S., \& Kalish, N. (2007). The case against homework: How homework is hurting children and what parents can do about it. New York: Harmony.

Bloom, B. S. (1969). Taxonomy of Educational Objectives: The Classification of Educational Goals. Boston: Addison-Wesley Longman.

Cheema, J. (2011). Mathematics Achievement: The role of homework and self-efficacy beliefs. Journal of Advanced Academics, 22, 310-339.

Cooper, H., Lindsay, J. J., Nye, B., \& Greathouse, S. (1998). Relationship among attitudes about homework, amount of home work assigned and completed and student achievement. Journal of Educational Psychology, 90(1), 70-83.

Doorn, D. J., Janssen, S., \& O'Brien M. (2010). Student attitude and approaches to online homework. International Journal for the Scholarship of Teaching and Learning, 4(1), 122. doi:10.20429/ijsotl.2010.040105

Fan, H., Xu, J, Cai,Z., He, J., \& Fan, X. (2017). Homework and students' in mathematics and science: a 30-year meta-analysis, 1986-2015. Educational Research Review, 20, 35-54.

Fernandez-Alonso, R., Alvarez-Diaz, M., Suarez-Alvarez, J., \& Muniz, J. (2017). Students' achievement and homework assignment strategies. Frontiers Psychology, 8, 1-11. doi:10.3389/fpsyg.2017.00286

Fernandez-Alonso, R., Suarez-Alvarez, J., \& Muniz, J. (2016). Homework and performance in mathematics: the role of the teacher, the family and the student's background. Revista de Psicodidáctica, 21(1), 5-23. doi:10.1387/RevPsicodidact.13939

Haddock, V. (2006, October 8). After years of teachers piling it on, there is a new movement to ... Abolish homework. The San Francisco Chronicle. Retrieved from https:// www.sfgate.com.

Howie, S. (2012). Third International Mathematics and Science Study Repeat (TIMSS-R) Executive Summary. Cape Town: HSCR Press.

Kohn, A. (2007). The homework myth, why our kids get too much of a bad thing. Cambridge, MA: Da Capo Press.

Landers, M., \& Reinholz D. (2015). Students' reflection on mathematics homework feedback. Journal of Developmental Education, 38(3), 22-31.

Olisama, O. V., \& Appah, R. O. (2010). A research on the extent of the use of ICT in Mathematics/Science education for a sustainable development. African Journal of Education Research and Administration, 3(1), 74-78.

Pablico, J. R., Diack, M., \& Lawson, A. (2017). Differentiated instruction in the high school science classroom: Qualitative and Quantitative Analysis. International Journal of Learning, Teaching and Educational Research, 16(7), 30-54.

Roschelle, J., Feng, M., Murphy, R. F., \& Mason, C. A. (2016). Online Mathematics Homework Increases Student Achievement. AERA Open, 2(4), 1-12. doi:10.1177/2332858416673968 


\section{Appendix}

An example of SMATHA or T.M.H.A. on fractions:

\section{Instruction: Attempt all questions.}

1. List five proper fractions, five improper fractions and five mixed numbers.

2. Arrange the following in both ascending and descending orders: $3 / 8,4 / 5,3 / 10$.

3. Simplify: $3 \frac{1 / 4}{4}+5 / 8+4 \frac{1}{2}-33 / 8$.

4. Simplify: $4 / 5 \div 3 / 5$ of $71 / 2$.

5. From my money, I spent $1 / 3$ and then $1 / 4$. Find $2 / 5$ of the remainder.

Note: Q1 (remembering), Q2-Q4 (understanding) and Q3 (application).

An example of a regular assignment constructed by one of the mathematics teachers.

1. Simplify: $7 \frac{5}{6}+2-2 \frac{5}{9}+1 \frac{1}{2}$.

2. Divide the difference between $3 / 4$ and $2 / 5$ by their product.

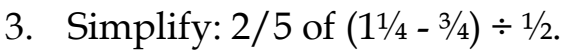

4. Express 250 as a fraction of $2 \frac{1}{2} \mathrm{~kg}$.

5. What must I add to $5 / 9$ of $90 \mathrm{~K}$ to make $3 / 4$ of $80 \mathrm{~K}$ ? 